\title{
Lessons from a simple ecological wastewater treatment technology for scientific research and advanced engineering
}

\author{
Akihiko Terada ${ }^{1}$ \\ Published online: 19 April 2019 \\ (c) Springer-Verlag GmbH Germany, part of Springer Nature 2019
}

On March 19, 2019, the United Nations World Water Development Report 2019 has been published (WWAP 2019). The report entitled "Leaving No One Behind" is a comprehensive review focusing on the status quo of water sanitation and hygiene (WASH) services and the challenges for inequalities based on human rights, societal and economic perspectives. As for the technological aspect of water purification, the report emphasizes that the development of a cost-effective and simple technology is significant in countries where WASH services are not sufficiently attained.

The report mentions that one promising technology is phytoremediation. I agree with the idea that a nature-based technology would suit the regions where infrastructures are not ready. A constructed wetland, where a phytoremediation technology is employed, could be the first option to remove contaminants in water. The technology harnesses potentials of wetland plants to adsorb contaminants and of endophytic, rhizobial and sediment microorganisms into, onto and adjacent to a plant root to decompose them into mineralized forms. A primary reason to get this implemented stems from the simplicity of a system and minimum requirement of maintenance. Phytoremediation can remove emerging contaminants, e.g., pharmaceuticals, polycyclic aromatic hydrocarbons and heavy metals, threatening to aquatic organisms and human health.

Despite a more straightforward principle of and less laborious maintenance for a phytoremediation technology than high-tech technologies implemented in urbanized wastewater treatment facilities, the degradation mechanisms are seemingly more intricate. The interaction between indigenous microorganisms and aquatic plants exerts a pivotal role. Intriguingly, plant root exudates activate rhizosphere

Akihiko Terada

akte@cc.tuat.ac.jp

1 Department of Chemical Engineering, Tokyo University of Agriculture and Technology, 2-24-16 Naka, Koganei, Tokyo 184-8588, Japan bacteria, enhancing the degradation of recalcitrant compounds (e.g., Toyama et al. 2011). Current research regarding the effect of plant exudates on the increase in bacterial activity (e.g., Guyonnet et al. 2018) likely broadens comprehensive understanding of plant-bacteria interactions and the applicability of a constructed wetland to varieties of contaminated sites.

In addition to these intriguing scientific findings, one can choose a suitable configuration of a constructed wetland, i.e., from various types of wetland plants and system configurations, depending on contaminated sites and climates. The scrutiny for the selection is necessary from the standpoint of interdisciplinary subjects covering microbiology, environmental, chemical, ecological and agricultural engineering.

Challenges remain. A phytoremediation-based technology relies on biochemical processes by the surrounding microorganisms, requiring a much longer time for contaminant degradation than chemical-based counterparts. Likewise, the harvest of a wetland plant is inevitable; otherwise, decaying a wetland plant would release organic carbon, which results in secondary pollution. Management and disposal of harvested wetland plants should be, therefore, taken into account.

Could a wetland plant add any asset except a role of water purification? As biomass as an aquatic plant in a constructed wetland, Phragmites australis, Typha latifolia, Cyperus papyrus and so on have been often planted (Wu et al. 2015). They have shown excellent performances of contaminant removal. However, one can wonder if there is alternative biomass capable of harvesting grains. For instance, can Oryza sativa, a.k.a. rice plant, be utilized as a surrogate? Are there any species highly resistant against high salinity, a toxic compound and high-temperature conditions? Needless to say, these plants should not accumulate contaminants into grains. The research field should be extended to molecular biology and agricultural science to elucidate a mechanism to deter accumulation of toxic compounds into grains (Luo et al., 2018) and to accomplish the selective breeding of a 
wetland plant which plausibly overcomes the challenges as mentioned above.

Another important trait, that we should not forget, is an oxygen delivery characteristic of a wetland plant. Oxygen is transferred via a stalk and finally supplied via root to the rhizosphere. Because of the delivered oxygen, the rhizosphere microorganisms can respire to enhance contaminant removals and mitigate greenhouse gas emission, e.g., methane oxidation by methanotrophs.

Analogous to the principle where oxygen is supplied from the plant lumen to the rhizosphere, the use of a gaspermeable membrane functioning as an oxygen-supplying material and bacterial carrier is emerging in the field of wastewater technology. A membrane-aerated biofilm reactor (MABR), where a module of gas-permeable membranes is mounted in a wastewater bioreactor vessel, has currently brought considerable attention. Gas supply by the lumen of a hollow-fiber membrane, an analogue of a stalk and root of a wetland plant, provides an excellent and efficient oxygen supply in a bubbleless form to a biofilm around a hollow fiber, facilitating contaminant removal. Also, the choice of a high oxygen-permeable material like silicone allows a substantial reduction of aeration cost for a wastewater treatment bioreactor. Given that aeration accounts to about half of the energy consumption of a wastewater treatment facility, an MABR is being scaled-up, which will appear in practice shortly as an alternative of a conventional activated sludge in developed countries.

This trend is based on the similar concept of an oxygen delivery mechanism seen in a wetland plant-an analogy existing in wastewater treatment technologies for developing and developed regions. It seems that scientific findings and innovation are still hidden or overlooked in natural environments and eco-technologies.

\section{References}

Guyonnet JP, Guillemet M, Dubost A, Simon L, Ortet P, Barrakat M, Heulin T, Achouak W, Haichar FE (2018) Plant nutrient resource use strategies shape active rhizosphere microbiota through root exudation. Front Plant Sci 9:13

Luo JS, Huang J, Zeng DL, Peng JS, Zhang GB, Ma HL, Guan Y, Yi HY, Fu YL, Han B, Lin HX, Qian Q, Gong JM (2018) A defensin-like protein drives cadmium efflux and allocation in rice. Nat Commun 9:9

Toyama T, Furukawa T, Maeda N, Inoue D, Sei K, Mori K, Kikuchi S, Ike M (2011) Accelerated biodegradation of pyrene and benzo a pyrene in the Phragmites australis rhizosphere by bacteria-root exudate interactions. Water Res 45(4):1629-1638

Wu HM, Zhang J, Ngo HH, Guo WS, Hu Z, Liang S, Fan JL, Liu H (2015) A review on the sustainability of constructed wetlands for wastewater treatment: design and operation. Biores Technol 175:594-601

WWAP (UNESCO World Water Assessment Programme) (2019) World water development report 2019: leaving no one behind. Paris

Publisher's Note Springer Nature remains neutral with regard to jurisdictional claims in published maps and institutional affiliations. 